\title{
Suppurative keratitis caused by Streptococcus pneumoniae after cataract surgery
}

\author{
David G Charteris, Mark Batterbury, Malcolm Armstrong, Andrew B Tullo
}

Manchester Royal Eye Hospital, Oxford Road, Manchester M13 9WH D G Charteris M Batterbury A B Tullo

\section{Microbiology}

Department, Manchester Royal Infirmary M Armstrong

Correspondence to: Mr D G Charteris, Moorfields Eye Hospital, City Road, London ECIV 2PD

Accepted for publication 7 July 1994

\section{Table 1 Patient details}

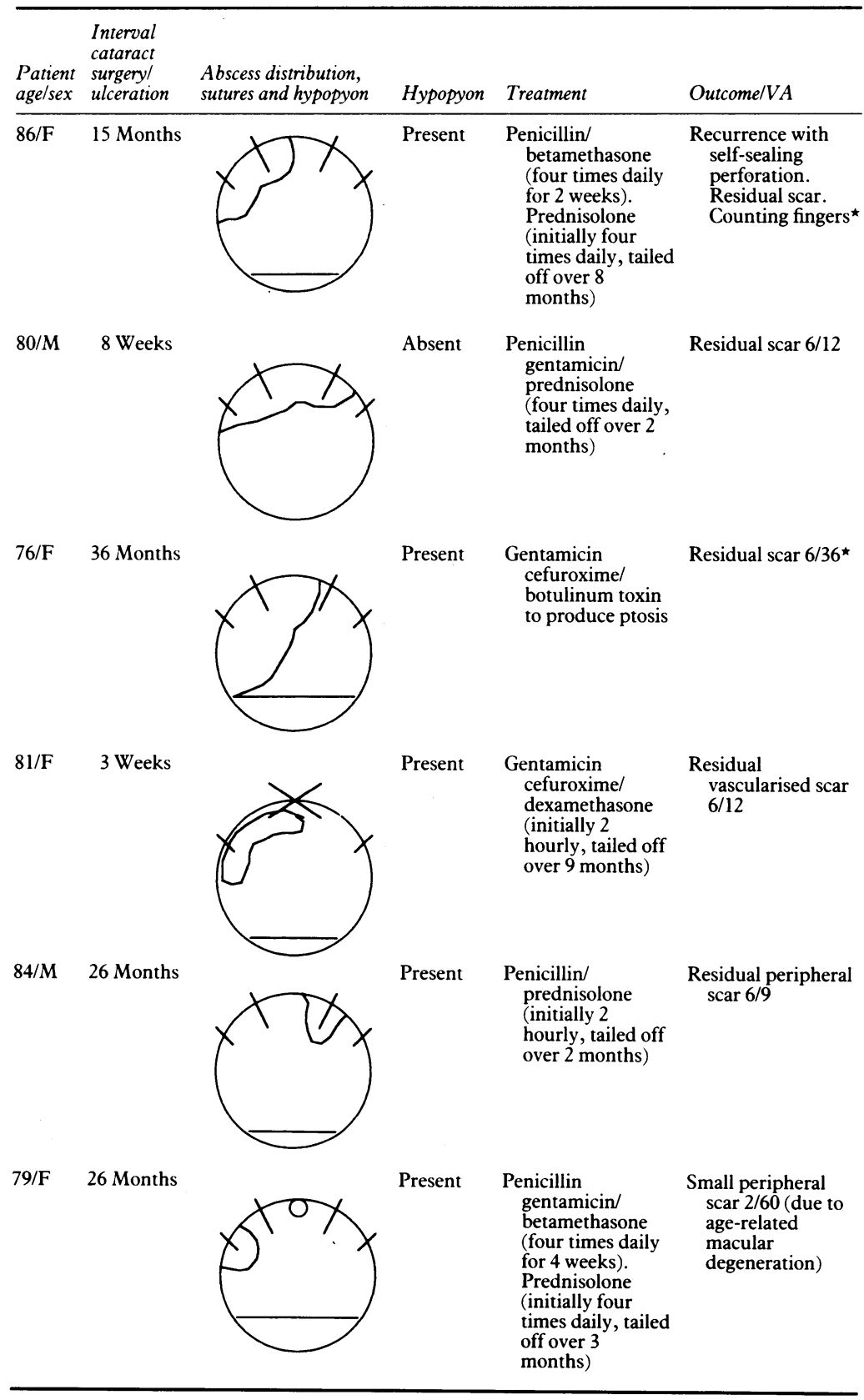

${ }^{\star}$ Cases where final visual acuity was attributable to corneal scarring.

\begin{abstract}
Six elderly patients are described (age range 76-86 years) in whom a characteristic peripheral suppurative keratitis developed 1-36 months after uncomplicated cataract surgery. A corneal section had been used in all patients and four or five interrupted nylon sutures were present at the time of onset. Streptococcus pneumoniae was cultured from a corneal scrape in all cases. Treatment with appropriate antibiotics resulted in slow resolution
\end{abstract}

Corneal ulceration and abscess formation due to infection with Streptococcus pneumoniae is classically described as a deep, oval central stromal ulceration accompanied by hypopyon formation and corneal thinning. ${ }^{2}$ Such ulcers may occur after trauma. While corneal abscess and endophthalmitis have been described as a consequence of nylon sutures following cataract and corneal graft surgery $^{3-5}$ none of these cases were known to be due to infection with $S$ pneumoniae. We report six recently observed patients with a characteristic peripheral corneal infection due to $S$ pneumoniae and related to cataract surgery sutures.

\section{Materials and methods}

Six patients with peripheral suppurative keratitis caused by $S$ pneumoniae, who had previously undergone cataract surgery at Manchester Royal Eye Hospital during the period 1988-93, were reviewed retrospectively.

Microbiological investigation was carried out as follows: material from the corneal ulcer was obtained by scraping with a sterile needle for a Gram stain. Further scrape specimens were used to inoculate a chocolate agar plate and agar blobs for enrichment culture. ${ }^{6}$ The media were incubated at $37^{\circ} \mathrm{C}$ in $6 \%$ carbon dioxide for up to 5 days.

\section{Results}

\section{PATIENT DATA}

Patient details are documented in Table 1 and illustrated in Figures 1 and 2. No association was found with concurrent upper respiratory infections in the patients or other family members. All six cases presented between the months of May and September.

All patients had uncomplicated extracapsular cataract surgery with intraocular lens implantation through a corneal section. In each case there was a relatively short history (1-14 days) of increasing ocular inflammation and disturbance of vision at the time of presentation. The cornea was significantly thinned at the site of the abscess in most cases and in one case this resulted in a small perforation which was self-sealing. Treatment was initially with intensive cefuroxime (50 $\mathrm{mg} / \mathrm{ml})$ and gentamicin $(15 \mathrm{mg} / \mathrm{ml})$ according to a standard procedure with subsequent modification after culture and sensitivity results were 
Figure 1 Slit-lamp photograph showing severe peripheral ulceration and infiltration (patient 2 in Table 1, sutures removed). Note related corneal folds.

Figure 2 Slit-lamp photograph showing hypopyon and abscess formation around nylon corneal suture (patient 5 , Table 1).

Figure 3 Photomicrograph of Gram stain of corneal scrape showing numerous capsulated Gram positive diplococci typical of $S$ pneumoniae. $\times 1450$.
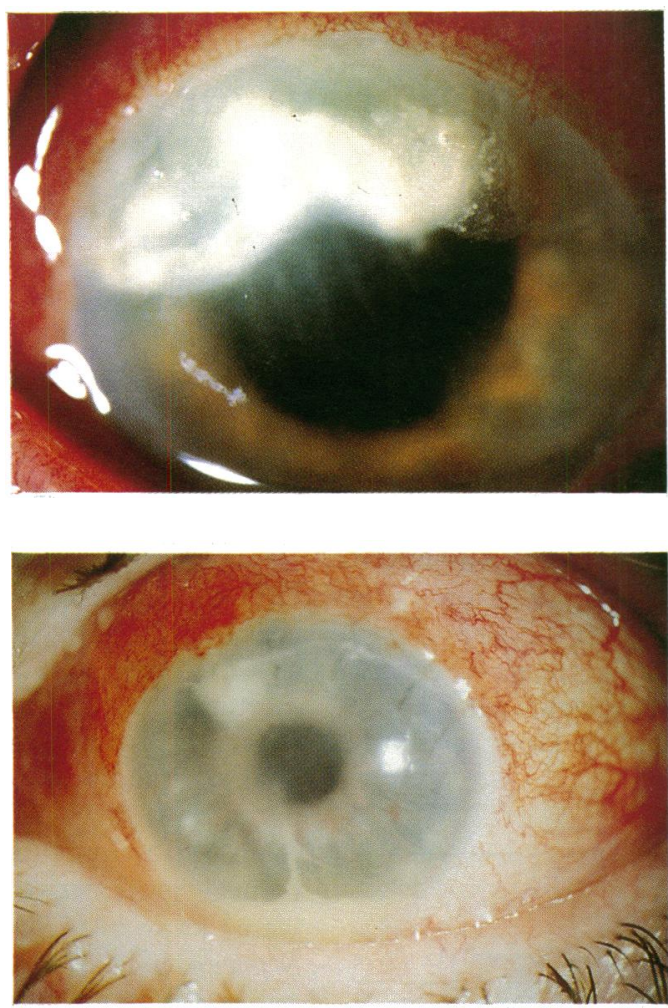

available. The causative organism was sensitive to penicillin in each case and the antibiotic regimen was modified accordingly (penicillin $2500 \mathrm{units} / \mathrm{ml}$ ) in five of the six cases. In the other patient gentamicin and cefuroxime were continued because of the initial favourable clinical response.

In four of the six cases sutures were found to be loose at the site of the abscess and residual sutures were removed in all patients. In five of the six cases topical steroids (prednisolone sodium phosphate $0.5 \%$, betamethasone sodium

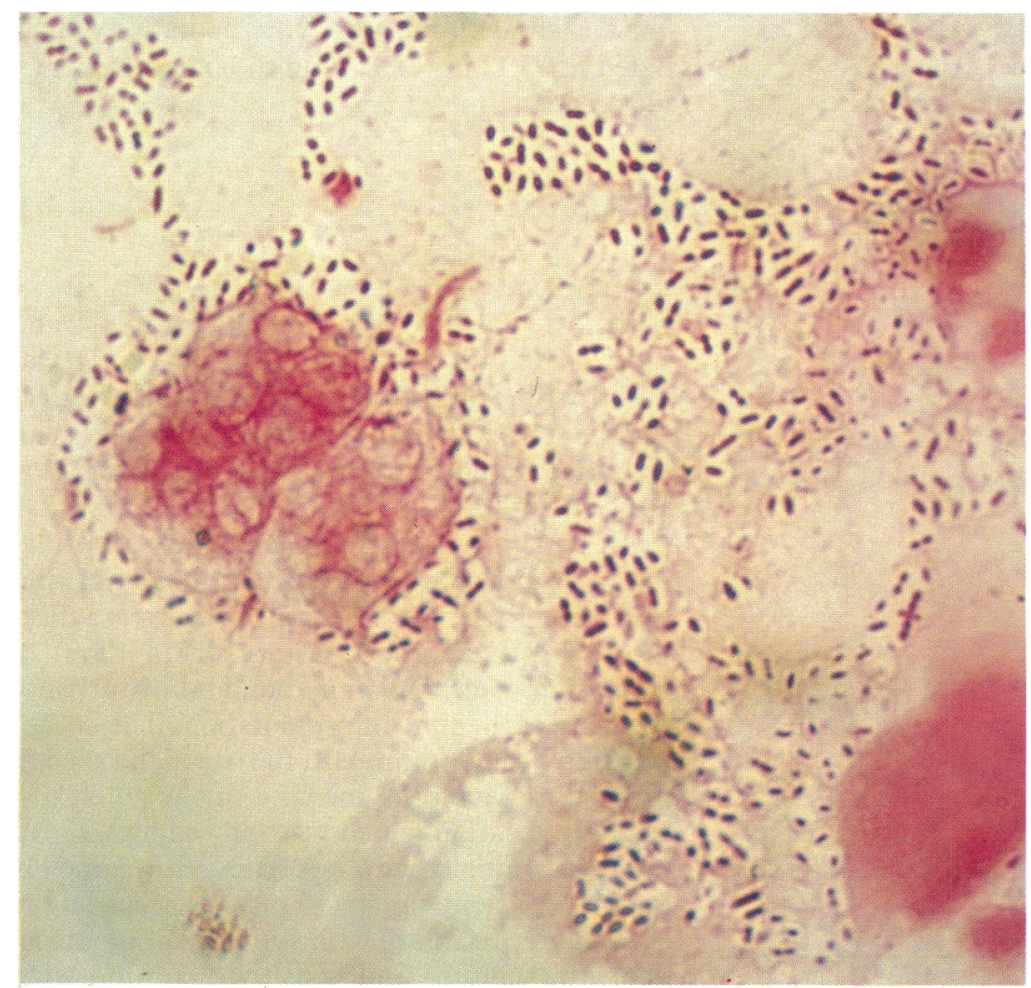

phosphate $0 \cdot 1 \%$, or dexamethasone $0 \cdot 1 \%$ ) were introduced at an early stage in treatment (Table 1). There was a clinical impression that steroid treatment appeared to accelerate resolution of the inflammation, and was maintained for several months in some cases. Despite appropriate antibacterial treatment the ulcers were notably chronic in course with significant residual corneal opacification in four cases.

\section{MICROBIOLOGY}

A corneal scrape yielded the organism in each case: in two a Gram stain showed Gram positive cocci and in all six $S$ pneumoniae was cultured from the scrape specimen. Bacterial growth was obtained in all cases on chocolate agar after 24 hours. $\alpha$ Haemolytic colonies, staining as Gram positive diplococci, were subsequently identified as $S$ pneumoniae (Fig 3) after a further 24 hours.

\section{Discussion}

The cases reported in this paper demonstrate that in addition to the classic central corneal ulcer caused by $S$ pneumoniae infection, peripheral corneal ulceration and abscess formation can also result from infection by this organism in relation to nylon sutures following cataract surgery. Previous reports ${ }^{3-5}$ of suture related corneal infection have not found $S$ pneumoniae to be a causative agent and the findings in this study would suggest that it may therefore have been underestimated as a pathogen in such cases. $S$ pneumoniae has, however, been found to be a common cause of infective keratitis at Manchester Royal Eye Hospital, notably in elderly patients. ${ }^{6} S$ pneumoniae has also recently been reported as a cause of late, severe corneoscleritis following pterygium removal and $\beta$ irradiation.?

The cases had a history of up to 2 weeks of increasing symptoms. The relatively advanced nature of the keratitis in most of the eyes may in part be due to the virulent nature of $S$ pneumoniae, and also to poor corneal sensation in the area of the section resulting in a delay in presentation. Notably there was marked thinning of the peripheral cornea and a small perforation in one case. The accumulation of inflammatory cells and subsequent enzymatic release is likely to be responsible for this local tissue destruction though it is possible that more specific immune mediated mechanisms (such as those involved in peripheral corneal melts) may also be involved in the destructive process. The clinical impression that early introduction of topical steroids accelerated resolution of the keratitis suggests that inflammatory tissue destruction, whether non-specific or immune mediated, is contributing to the protracted nature of the corneal inflammation seen in these cases. All cases had residual scarring which, in general, was related to the distribution of the initial corneal infiltrate. Two patients have lasting visual impairment attributable to the corneal scarring.

We feel that the clinical pattern observed in these cases is strongly suggestive of infection 
with $S$ pneumoniae. However, broad spectrum antibiotics remain the optimal initial treatment since (a) the clinical appearance of a corneal infection can never be completely pathognomonic, and (b) $S$ pneumoniae is widely sensitive to antibiotics such as cefuroxime.

The cataract operations were performed by a different surgeon in each of the six cases. Four of the six patients presented at a late stage (1-3 years) after their cataract surgery. Thus, it seems unlikely that infection was acquired at the time of surgery. It is possible that the keratitis may be related to nylon suture hydrolysis which has been proposed as an aetiological factor in suture related pathology in a previous report. ${ }^{3}$ Notably, four of the six cases had loose sutures at the abscess site, although it is possible that this could be a consequence of local inflammation and tissue destruction. It has been shown that 80 $90 \%$ of patients with cataract surgery corneal sections sutured with $10 / 0$ nylon have broken sutures 2-3 years after surgery and that these are often symptomatic. ${ }^{8}$ Exposed monofilament sutures are recognised to cause a variety of symptoms and signs including foreign body sensation, tearing, giant papillary conjunctivitis, tarsal ulceration, and corneal infiltration. ${ }^{9} \mathrm{We}$ would advocate the removal of any such broken or loose corneal sutures. In addition, the occurrence of suture related infection in the cases reported above lends further support for the policy that after cataract surgery nylon corneal sutures should routinely be removed.

1 Liesegang TJ. Bacterial and fungal keratitis. In: Kaufmann $\mathrm{HE}$, Barron $\mathrm{BA}$, McDonald MB, Waltmann SR, eds. The cornea. New York: Churchill Livingstone, 1988:225.

2 Arffa RC. Grayson's diseases of the cornea. 3rd ed. St Louis: Mosby, 1991: 172-3.

3 Acheson JF, Lyons CJ. Ocular morbidity due to monofilament nylon corneal sutures. Eye 1991; 5: 106-12.

4 Confino J, Brown SI. Bacterial endophthalmitis associated with exposed monofilament sutures following corneal transplantation. Am f Ophthalmol 1985; 99: 111-3.

5 Gelander H. Bacterial endophthalmitis following cutting of sutures after cataract surgery. Am $\mathcal{F}$ Ophthalmol 1982; 94: 528-33.

6 Armstrong $M$. The laboratory investigation of infective keratitis. Brf Biomed Sci 1994 (in press)

7 Moriarty AP, Crawford GJ, McAllister IL, Constable IJ Bilateral streptococcal corneoscleritis complicating $\beta$ irradiation induced scleral necrosis. Br f Ophthalmol 1993; 77: tion ind $251-2$.

8 Jackson $\mathrm{H}$, Bosanquet R. Should nylon corneal sutures be routinely removed? Brf Ophthalmol 1991; 75: 663-4.

9 Nirankari VS, Karesh JW, Richards RD. Complications of exposed monofilament sutures. Am $\mathcal{F}$ Ophthalmol 1983; 95: 515-9. 